\title{
Early Development of a Design Methodology for Harvesting Natural Resources in Buildings
}

\author{
Kereshmeh Afsari \\ Purdue University, USA \\ kafsari@purdue.edu \\ Matthew Swarts \\ Georgia Institute of Technology, USA \\ matthew.swarts@design.gatech.edu \\ John Haymaker
Perkins+Will, USA
john.haymaker@perkinswill.com
}

\author{
Marcelo Bernal \\ Universidad Técnica Federico Santa María, Chile \\ marcelo.bernal@usm.cl
}

Tyrone Marshall

Perkins+Will, USA

Tyrone.Marshall@perkinswill.com

Katherine Martin

Georgia Institute of Technology, USA

kmartin60@gatech.edu

\begin{abstract}
Our cities have centrally distributed utility systems and therefore, harvesting natural resources is typically managed centrally. Even though there are several natural resources that can be harvested from the building envelope such as daylight, water, wind, vegetation, and energy, resource harvesting locally has not been considered as a function of individual building performance. Harvesting renewable resources in individual buildings is a critical step towards creating sustainable and resilient buildings. This paper investigates methods for resource harvesting from the building envelope and indicates how multiple harvesting methods with different performance objectives can be integrated in the building design through a performance-based design approach.
\end{abstract}

Keywords: Resource Harvesting; Building Envelope; Performance-based Design; Design Parameters; Design Space Construction

\section{Introduction}

Our cities have centrally distributed utility systems and therefore, typically harvesting of natural resources is managed centrally. Thus, resource harvesting locally has not been typically considered in the building design especially as a function of individual building performance. On the other hand, building envelopes mediate the inside environment from the outside through reflection, transmission, and absorption of resources (Kilbert, 2016). There are many natural resources that can be harvested from the building envelope such as daylight, water, wind, vegetation, and energy. By including sustainable design features within the buildings, the operation costs and environmental impacts can be reduced and building resiliency can be increased. Particularly, maximizing the use of renewable resources will increase energy independence (NIBS, 2017). Therefore, harvesting renewable resources in individual buildings is a critical step towards creating sustainable and resilient buildings.

This paper highlights that integrating complex harvesting systems in the buildings requires careful analysis and the application of a performance-based design approach. The goal of this paper is to investigate methods for resource harvesting from the building envelope, to indicate how selected harvesting methods with different performance objectives can be integrated in the building design through a performance-based design approach, and to demonstrate key performance indicators within the design parameters that can assist or affect the integration of these resource harvesting systems. In this paper, first, the significance of natural resource harvesting in the buildings is identified and the methods of natural resource harvesting from the building envelope are studied. Then, through an empirical study the paper demonstrates how a performance-based design framework can assist with the decision-making in the design process and enables the integration of harvesting techniques with the building design.

\section{Natural Resource Harvesting in Buildings}

Many studies have indicated the significance of resilience in facilitating sustainable development in a changing world where surprise and transformation are inevitable (Folke et al., 2002). Resilient systems such as buildings can cope and adapt to the surprise without the help of auxiliary services, and it is necessary to embed the perspective for resilience in strategic development activities (Folke et al., 2002) such as building design. Also, a shift to the use of renewable resources in buildings is necessary as non-renewables will eventually disappear (Kilbert, 2016). Renewable resources will help to reduce environmental impact of the buildings. For instance, rainwater harvesting increases water accessibility and reduces local environment impacts (Domenech \& Suri, 2011). Most importantly, rainwater harvesting at the individual building makes those buildings more resilient to sudden changes such as floods and local groundwater or utility pollution (Domenech \& Suri, 2011; Novak et Al., 2014).

Current design methodologies rarely focus on more than one resource harvesting method. There is a lack of design methodology for the integration of multiple harvesting methods in buildings with different and often conflicting systems. In fact, the combination of multiple resource harvesting methods requires the resolution of conflicting performance objectives, because each harvesting system may set different goal prioritization than others. For this purpose, a proper optimization method should be applied. One of the multiobjective optimization methods for sustainable building design 
is known as Pareto optimization in which "a range of solutions are sought that spans the tradeoff between each objective" (Evins, 2013). We applied this multi-objective optimization in this study to guide the decision-making process in the presence of tradeoffs between conflicting objectives in natural resource harvesting techniques. The study applies Design Space Construction (DSC) framework which is explained in the following section, as the multi-objective optimization methodology in the design process of four case studies.

In addition, there are many natural resource harvesting technologies that can be used in buildings. In fact, a shift toward any kind of renewable resources is essential in achieving high-performance buildings that rely on renewable resources for many purposes such as energy systems, reuse of water, integration of native plants, and ventilation. These approaches can minimize environmental impact and resource consumption (Kilbert, 2016). In this study two categories of resource harvesting systems are identified: 1) generic harvesting methods that could be integrated in the buildings and can adapt to any climate; and, 2) climate-specific harvesting methods that depend on the availability of the natural resources at the building site. Here, a combination of harvesting technologies is applied and the optimization is considered throughout the iterative design process.

Also, design factors can affect resource harvesting and among these factors on which this study emphasizes are: 1) Building type and program; 2) Climate; 3) Resource harvesting methods; and 4) Design intent and building geometry. Other factors such as materials can have significant impact on the system and on the design but are not included in this study.

\section{Design Space Construction Framework}

A performance-based design framework known as Design Space Construction or DSC (Haymaker et al., 2017) which is developed by Perkins+Will architecture firm was applied in this study to guide the design process. The DSC multi-criteria design approach aims at maximizing the value of design decisions by a process including the following steps:

- Problem formulation

- Generation of design alternatives

- Impact analysis

- Value assessment

Problem formulation is the translation of goals into performance objectives to achieve, constraints to avoid, and the representation of stakeholder's preferences in terms of weighting factors. The generation of design alternatives correspond to the resulting population of solutions derived from all possible combination of options for every variable of the design problem. In this particular study, four different families of alternatives were generated in each case. The impact analysis estimates the influence of the options of an alternative in its performance on each objective. Finally, value assessment is the synthesis of performance impacts. The implementation of this framework relies on parametric modeling technology for the automatic generation of the alternatives, interfacing with analysis engines, and a webbased parallel coordinate plot for multidimensional data visualization to support interactive comparison and decision making.

\section{Design Process}

The integration of natural resource harvesting with the design of buildings was developed and led by the authors in an undergraduate vertical design studio at the Georgia Institute of Technology. The project features a collaboration with Perkins+Will architecture firm. In this studio, twelve senior and junior undergraduate students formed four teams of three students to collaborate on one project per team. The goal was to design a Child Care Center facility that harvests local resources. Each Child Care Center was designed for different cities under different climate zone categories. The teams initially studied the spatial program, site analysis, design precedents, and selected natural resource harvesting techniques. Key design factors shared across the four projects were building type and program as well as generic resource harvesting techniques. The site, climate, building concept and form varied in each project as will be explained later.

\section{Performance Objectives}

The teams defined performance objectives as well as performance indicators (Table 1), developed a schematic design and then applied computational design methods and performance-based approaches to create a responsive building that facilitates natural resource harvesting from the building envelope. The buildings were also required to assure nurturing, dependable, exceptional and safe care for children outside the home and accommodate the needs of children for daytime childcare. In addition to these objectives, each team defined a set of objectives based on the climate-specific harvesting methods selected for their project which will be explained in the "Case Studies" section.

Table 1: Performance objectives and indicators

\begin{tabular}{|lll|}
\hline $\begin{array}{l}\text { Performance } \\
\text { Factor }\end{array}$ & Objective & Performance Indicator \\
\hline Plant harvesting & Maximize & Hydroponic wall area (sqft) \\
\hline Daylight quality & Maximize & Daylight factor \\
\hline Energy consumption & Minimize & $\begin{array}{l}\text { Total thermal energy (kWh) } \\
\text { Heating load (kWh) } \\
\text { Derived Parameters: } \\
\text { Window/Wall Ratio (WWR) }\end{array}$ \\
\hline \begin{tabular}{lll|} 
Energy harvesting \\
from the floor
\end{tabular} & Maximize & $\begin{array}{l}\text { Indoor playground/corridors } \\
\text { area (sqft) }\end{array}$ \\
\hline Circulation distance & Minimize & Max travel distance (ft) \\
\hline Outdoor playground & Maximize & Outdoor play area (sqft) \\
\hline $\begin{array}{l}\text { Classrooms and } \\
\text { support spaces }\end{array}$ & Maximize & Gross floor area (sqft) \\
\hline
\end{tabular}

\section{Building Type and Program}

Child Care Center buildings provide the opportunity to engage children with resource harvesting techniques, making the harvesting technologies useful for educational purposes. The spatial program for the building was based on a case study of 
a Child Care Center developed by Perkins+Will architecture firm. The base program suggested a total of 40,000 sqft for the building spaces, excluding circulation. In the spatial program, the classrooms and their support spaces are categorized into three age groups: infant/toddler, transition twos, and pre-k (i.e. pre-kindergarten). Alternatively, there are spaces for kindergarten classroom and associated laboratories that could be added to the building if the site allows the provision of these spaces. Modifications could be applied to the program as it responded to the site restrictions.

\section{Climate}

For these four projects, four different locations were assigned and each offered a different climate condition. The diverse locations were selected according to their ASHRAE Standard 169-2013 for the climatic building design opportunities that each may provide for the Child Care Center program (ANSI/ASHRAE 169-2013, 2013). Thus, each site could potentially provide a different set of natural resources to harvest. These four cities include: Boston (5A), Los Angeles (3B), Minneapolis (6A), and Miami (1A).

\section{Resource Harvesting Methods}

In this study, three general and a fourth specific resourceharvesting system as shown in Table 2 , were supposed to be integrated into the design of each building.

Table 2: Resource Harvesting Systems

\begin{tabular}{|l|l|}
\hline Resource Harvesting Systems & Type \\
\hline $\begin{array}{l}\text { 1. Daylighting to harvest natural lighting } \\
\text { 2. Hydroponic wall system to harvest native } \\
\text { plants on the exterior walls. }\end{array}$ & General \\
\hline $\begin{array}{l}\text { 3. Triboelectric flooring system to harvest } \\
\text { energy within the building from the movement } \\
\text { of children. }\end{array}$ & General \\
\hline $\begin{array}{l}\text { 4. Climate-specific harvesting system based on } \\
\text { the available natural resources at each site. }\end{array}$ & Specific \\
\hline
\end{tabular}

Daylight Analysis: For the daylighting analysis, the DSC methodology was used to calculate the daylight quantity and quality within the spaces. The daylight simulation in this method calculates the daylight factor, which is "the ratio between the interior and exterior illuminance level of natural lighting" (Haymaker et al., 2017).

For the second and third system, as explained below, the teams collaborated with two teams of Mechanical Engineering students from Georgia Tech's College of Engineering to design and implement the harvesting systems in the Child Care Center buildings. For the fourth resource harvesting system, each of the four teams included a climate-specific solution that can harvest a specific natural resource available in the project's site and can be integrated within the design of the building. These systems are explained for each project separately in the "Case Studies" section.

Hydroponic Wall System: This modular green wall system (Cho, et al., 2017) allows harvesting of native plants, adapts to the exterior geometry of the building, and complements the building's aesthetics. The system as shown in Figure 1 was designed with four main components: 1) a mounting hardware system that securely attaches the system to the exterior wall of the building, 2) a watering system, as shown in Figure 2, that utilizes a drip irrigation technique with flexible and hard line tubing and custom made nozzles that can fit easily into the hydroponic growing medium i.e. Rockwool, 3) a smart automatic watering system that has moisture sensors, a control module, and solenoids and can self-diagnose what each module needs for water and nutrients, 4) the outer shell with an equilateral triangle or a square module with a back plate and side pieces that snap fit together.

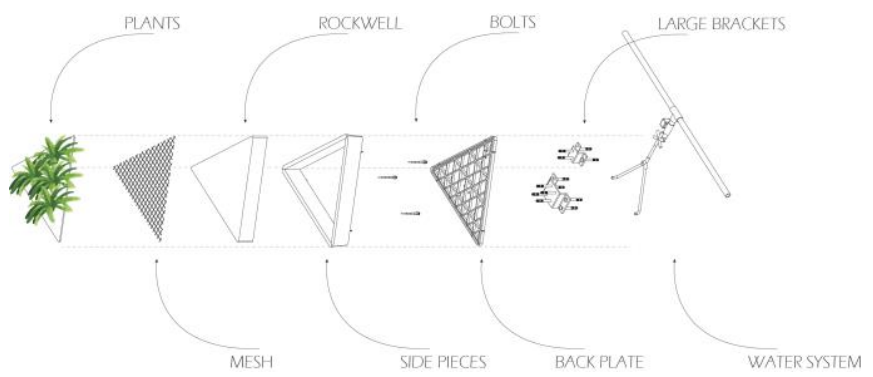

Figure 1: Exploded axonometric of the hydroponic wall with triangle module

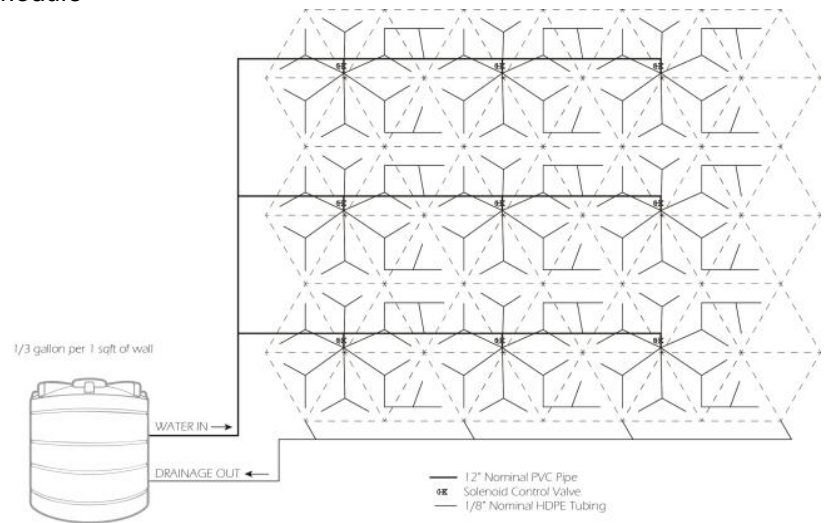

Figure 2: An example of wall modules combined for water delivery system

Triboelectric Flooring System: this flooring system (McGee, et al., 2017) is designed to harvest energy from the footsteps of children aged 2-6 to power an interactive installation. This selfpowered flooring system, as shown in Figure 3 and 4, generates peaks of up to $0.5 \mathrm{~W} / \mathrm{sqft}$ and allows children to safely interact with it. The system is also capable of withstanding forces generated from adults and reasonably larger forces distributed over a small area. The triboelectric nanogenerators (TENGs) capture static electricity which is created from the separation and contact of two materials with opposite triboelectric polarities (Wang, 2014). Here, the electron transfer between the materials is harvested into a usable form. Each tile of this system incorporates a suspension system which properly aligns the TENG layers of the stack such that the system can harvest the energy created from the contact and separation of each set of layers. The suspension system incorporates springs, which provide a rebound force that returns the tile to its initial configuration when the compressive force is removed as well as rails, which prevent bending, and torsional moments by keeping the system axially 
aligned. Each layer of the stack is composed of a substrate that is coated on both sides with a conductor, on one side with a positive dielectric and the other with a negative dielectric. The energy, which is harvested by this system, is used to power visual feedback LEDs that illuminate upon the application and release of a compressive force. This design and implementation is the first application of TENG technology for buildings. If a 19-tile system were compressed once every 30 seconds, for just 1 hour each day, the power harvested per year would be up to 29 kilowatt-hours.

Climate-specific harvesting systems are explained later in "Case Studies" section for each project.

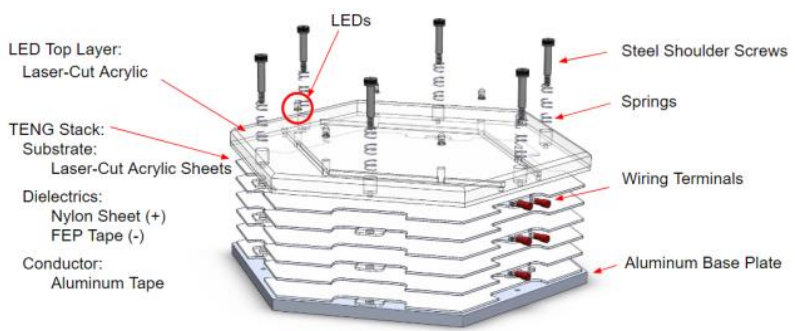

Figure 3: Exploded axonometric of the module of the triboelectric flooring systems

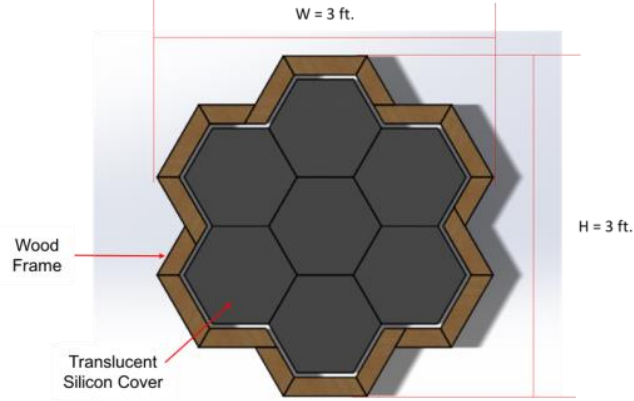

Figure 4: An example of the flooring modules combination

\section{Design Phases}

The design process consisted of several phases. During each phase, several layers of work that include the spatial programming, analysis of precedents, site analysis, design, and performance analysis progressed simultaneously. The students were expected to create multiple iterations to backtrack, research, test and re-test their designs.

Phase 1 consisted of study and analysis of each team's designated site as well as precedents in resource harvesting, such as water, solar energy, wind, vegetation, and air flow. Teams studied the urban fabric, site conditions, climate zones and environmental studies, resource harvesting techniques, building envelope systems, geometry factors, etc.

Phase 2 focused on Sprout Space, a product developed from the DSC methodology for a parametric modular classroom that integrates energy, daylighting and view analysis with the building design. The process includes decision formulation, alternative generations, performance analysis, data analysis and decision making.
Phase 3 explored the Child Care Center design development. The goal was to apply the methodologies developed in previous phases to the design of a responsive Child Care Center that facilitates natural resource harvesting from the building envelope, assured nurturing and dependable safety for the children. Initially, team members were tasked to individually design a concept that incorporates the team's findings from the previous phases and explore the design of the Child Care Center. The teams also completed studies of the spatial requirements, tectonics, circulation and user analysis. Then, the teams regrouped, completed a comparative analysis, and combined the individual design findings based on the performance objectives.

\section{Case Studies}

Each of the projects addressed site specific and building design strategies for integrating daylighting, deployment of a hydroponic wall system, and a triboelectric flooring system as explained above. A specific resource harvesting system is also considered that is focused on the unique opportunities for each of the different sites.

\section{Project 1: Boston}

Site: The site, as shown in Figure 5, is in South Boston, a previous industrial park, and is surrounded by underdeveloped lots and recently renovated buildings connecting the South Boston neighborhoods to downtown Boston.

Climate: Boston is in ASHRAE Climate Zone 5A characterized by a cool and humid climate. There is an average amount of sunlight but almost half of every month is characterized by overcast days. There is a moderate amount of precipitation but some of the moisture in the air stays as humidity.

Climate-specific Resource Harvesting Method: The high percentage of overcast days do not support solar energy harvesting systems. The average amount of precipitation is not significant for strategies that harvest snow or rainwater. However, Boston has the highest average wind speed of any major US city, including Chicago (ASHRAE and Kuehn, 2005). Therefore, the relationship between the building form and wind harvesting technology was explored as shown in Figure 6. Also, the performance objectives and performance indicators for wind energy harvesting in this project are summarized in Table 3.
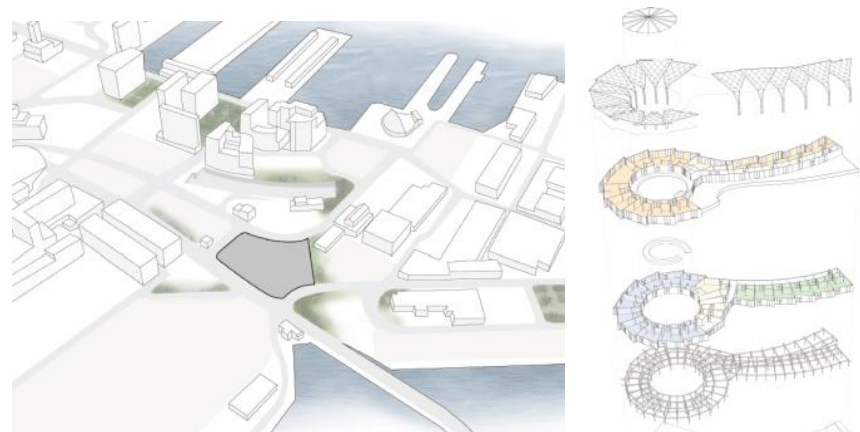

Figure 5: Left: Boston project site (in grey) and surrounded massing; Right: Exploded axonometric of the Boston project final design 


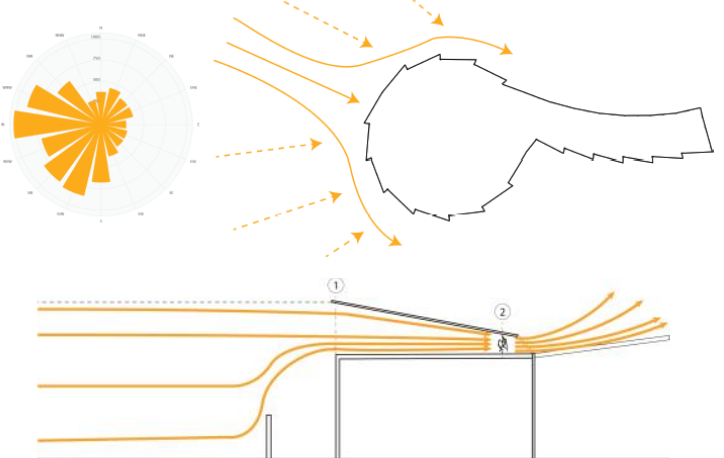

Figure 6: Top left: Prevailing wind in Boston; Top right: Boston project orientation for wind harvesting; Bottom: Diagram showing the design of the sails to perform as wind channels in the roof.

Table 3: Boston project performance objectives for wind harvesting

\begin{tabular}{lll|}
$\begin{array}{l}\text { Performance } \\
\text { Factor }\end{array}$ & Objective & Performance Indicator \\
\hline Wind energy & Maximize & Energy produced annually \\
harvesting & & using 10 turbines $(\mathrm{kWh})$ \\
& Derived Parameters: \\
& Roof slope (degrees) \\
& Building height (ft) \\
& Orientation (degrees) \\
\hline
\end{tabular}

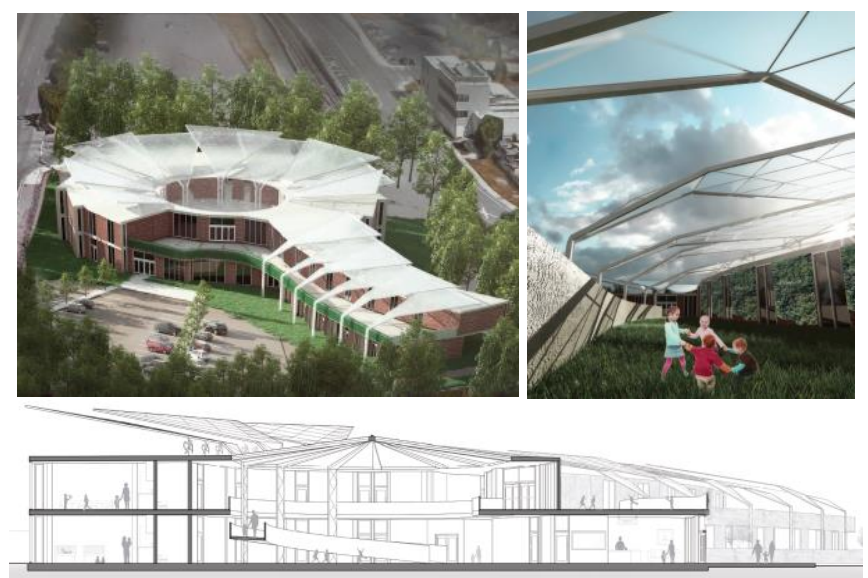

Figure 7: Top: Boston project final design; Bottom: Section through the atrium showing the wind channel on the roof

Design: After examining each of the individual designs, the team identified the strongest concepts in each individual design to inform the final design: a focal atrium with ramps, a sloped roof to enable wind harvesting, and clear definition of indoor and outdoor spaces. The team analyzed the orientation of the building to maximize southern exposure and improve their strategy for wind harvesting. Through this analysis, the team created the overall massing of the project and employed OpenFoam to explore the behavior of wind as it interacts with a building form. The team performed the DSC performancebased analysis to determine the optimal tradeoffs. The final design, shown in Figure 7 , is characterized by sculptural geometric "sails" which serve to channel the wind to increase pressure and energy output of helical wind turbines installed along the roof. The comparative analysis was performed based on the performance objectives. The building form, building orientation as well as the sail form and orientation are informed by the analysis performed for wind, energy loads, and daylighting. The project's core space is a large indoor play space that also functions as the entry atrium. The atrium features an arc with classrooms arrayed along it for capture of natural daylight. The activated atrium and classrooms achieve performance objectives for minimizing circulation distance for the project. The triboelectric flooring system integrates into the atrium flooring to create an interactive learning zone for children while harvesting energy from the floor. The building also opens to the south to increase daylighting and solar gain, provide views to the neighboring harbor and maximize the surface for plant harvesting along the hydroponic walls.

\section{Project 2: Los Angeles}

Site: The project's site is in a residential district near the Los Angeles River and along a major thoroughfare over the river to the rest of the city.

Climate: Los Angeles is in 3B ASHRAE climate zone and is characterized by a warm-dry climate. There is an abundance of sunlight and heat with low amounts of precipitation and cloud cover. There is little to no humidity. The effects of global warming and climate change have the potential to increase the intense, hot conditions (United States Environmental Protection Agency, 2016).

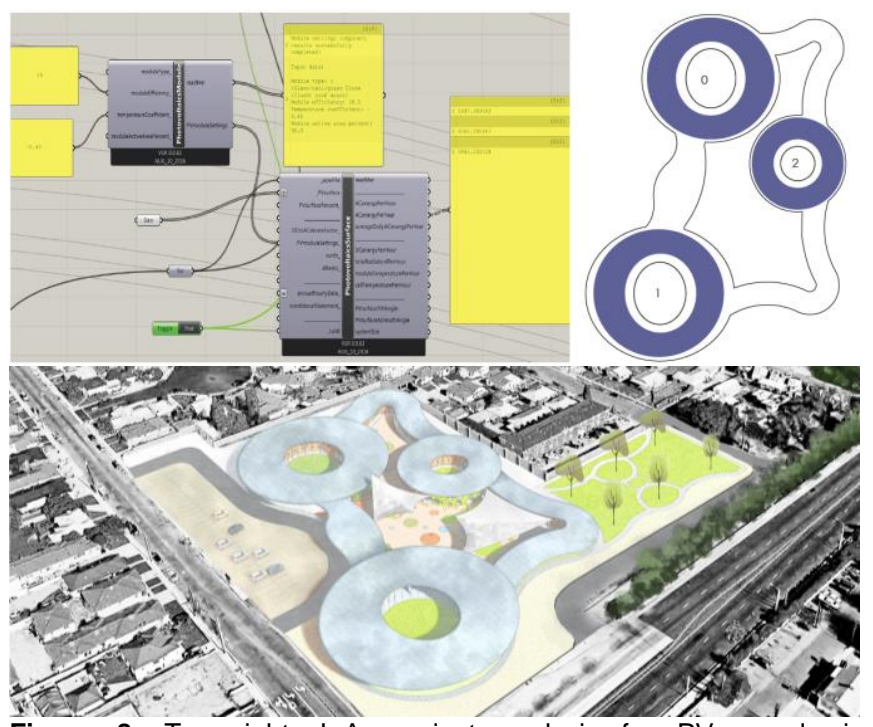

Figure 8: Top right: L.A. project analysis for PV panels in Grasshopper; Top left: Schematic plan with the location of PV cells marked in purple; Bottom: L.A. final building mass

Climate-specific Resource Harvesting Method: The site experiences consistent sunny days throughout the year. Thus, the effects of building form on solar gain and cooling energy efficiency were important to consider and estimated through parametric modeling with Grasshopper and analysis algorithms as shown in Figure 8. The climate-specific harvesting method for the project location that affords the most opportunity is solar energy harvesting. The team analyzed the effects of roof slope and building geometry on the efficiency of solar energy harvesting from the roof using thin film solar photovoltaic (PV) cells. Thin film PV cells have higher efficiency, have lower temperature coefficient than standard 
silicon PV panels (Shah et al, 1999; Chopra \& Dos, 1983), and they have flexible geometry thus, can be installed on curved surfaces. While standard PV panels perform best under direct sunlight, thin film PV cells are less affected by shading. Table 4 shows the performance objectives and performance indicators for climate-specific resource harvesting method in this project. Design alternatives were explored with a comparative analysis informed by these performance objectives.

Table 4: L.A. project performance objectives for solar energy harvesting

\begin{tabular}{|c|c|c|}
\hline $\begin{array}{l}\text { Performance } \\
\text { Factor }\end{array}$ & Objective & Performance Indicator \\
\hline $\begin{array}{l}\text { Solar energy } \\
\text { harvesting }\end{array}$ & Maximize & $\begin{array}{l}\text { Energy harvested annually } \\
\text { (kWh) } \\
\text { Derived Parameters: } \\
\text { Roof area (sqft) } \\
\text { Roof slope (degrees) } \\
\text { Orientation (degrees) } \\
\text { PV surface (sqft) }\end{array}$ \\
\hline
\end{tabular}

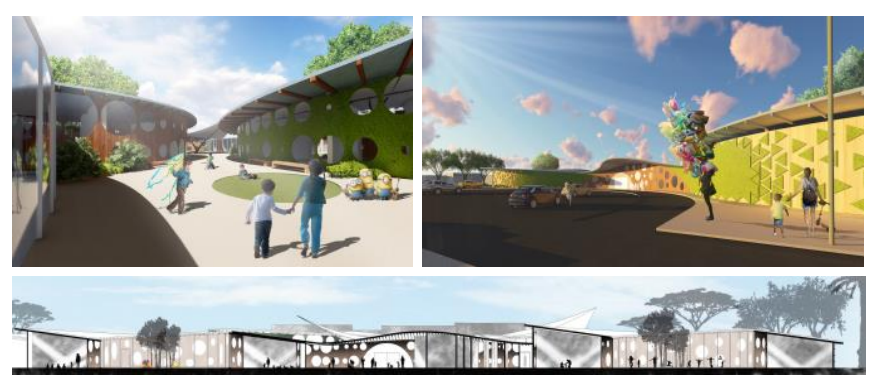

Figure 9: Top: L.A project final design; Bottom: Section through the building entrance
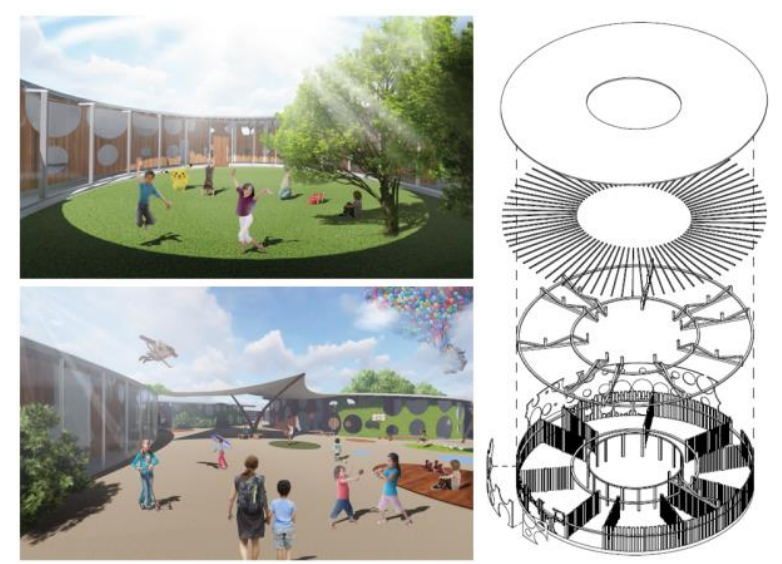

Figure 10: Left: Courtyards for each age group; Right: Exploded axonometric of one "village" of classrooms.

Design: The team explored a concept that featured a series of courtyards designated for each of the age groups to create "villages" of classrooms to make the building enjoyable for kids. The emphasis on inwardness in the building concept spoke to the crime rate of the area and the required safety of the children. The project considered the benefits of continuous circulation along the courtyards to create a smooth transition between classrooms and playground. After examining each of the individual designs, the team identified the strongest concepts to inform their final design shown in Figure 9 and 10: the individual courtyards and villages for the specific age groups, the freeform shaped roof utilizing thin film solar cells for energy harvesting, and a dynamic building form and exterior façade to engage with the community. The building envelope employed a series of hydroponic panels to enclose the building yet offer a connection with its surroundings without compromising the children's safety. The triboelectric flooring system was incorporated into the indoor play spaces to facilitate interactive learning experiences. The analysis for energy consumption and daylighting informed the spatial configuration, the form of the roof, as well as the façade during the design process.

\section{Project 3: Minneapolis}

Site: The project's site is in a neighborhood known as Falcon Heights in St. Paul and is on the outskirts of a large residential area. Just south of the site is the State Fair grounds.

Climate: Minneapolis is in 6A ASHRAE climate zone, characterized by a cold-humid climate. There is a high level of precipitation and lower temperatures throughout the year.
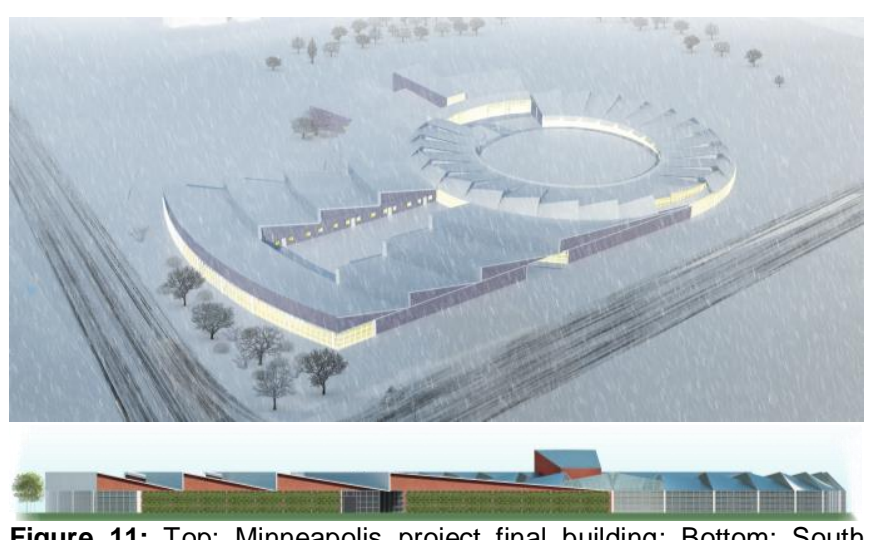

Figure 11: Top: Minneapolis project final building; Bottom: South elevation of the building

Climate-specific Resource Harvesting Method: This project focuses on water harvesting techniques including rainfall and snowfall considering the effect of the sun on these systems. The effect of the roof slope and geometry on efficiency of precipitation collection were analyzed through an iterative process. During the second phase of the project, the team studied the effects of building form on water and snow harvesting. The performance objective and performance indicators for climate-specific resource harvesting in this project are summarized in Table 5.

Table 5: Minneapolis project performance objectives for snow and rain harvesting

\begin{tabular}{|lll|}
$\begin{array}{l}\text { Performance } \\
\text { Factor }\end{array}$ & Objective & Performance Indicator \\
\hline Snow and rain & Maximize & Annual collected water \\
harvesting & & (gallons) \\
& Derived Parameters: \\
& Roof area (sqft) \\
& Roof slope (degrees) \\
\hline
\end{tabular}


Design: One of the main concepts in this project was based on separating infant/toddler spaces from transition twos and pre$\mathrm{k}$ with the provision of a separate outdoor play area for each so that the younger kids can be better protected. A comparative analysis informed by performance objectives was the basis for exploring the design alternatives. After examining each of the individual designs, the team identified the strongest concepts to be integrated in the final building: two courtyards that differentiate between the age groups, a dynamic form for an efficient roof system, and the clear distinction between classroom and administration programmatic spaces. The geometric shape of the final building shown in Figure 11, was informed by the data of precipitation collection, building orientation, and circulation patterns. The roof's circular form allows it to maximize the amount of precipitation it can capture. The roof as shown in Figure 12, was designed to direct the collected water to the circular courtyard where a tank is maintained under the ground for storing the water. The building form follows the prevailing wind direction to allow precipitation harvesting throughout the year. The building envelope utilizes the hydroponic wall paneling system to encourage gardening and outdoor learning experiences for the children. The design also explored the structural integrity between a full wall hydroponic system versus pods of panels. The triboelectric flooring system is partly covered with carpet to enable the installation within the multi-purpose spaces in addition to indoor play areas.

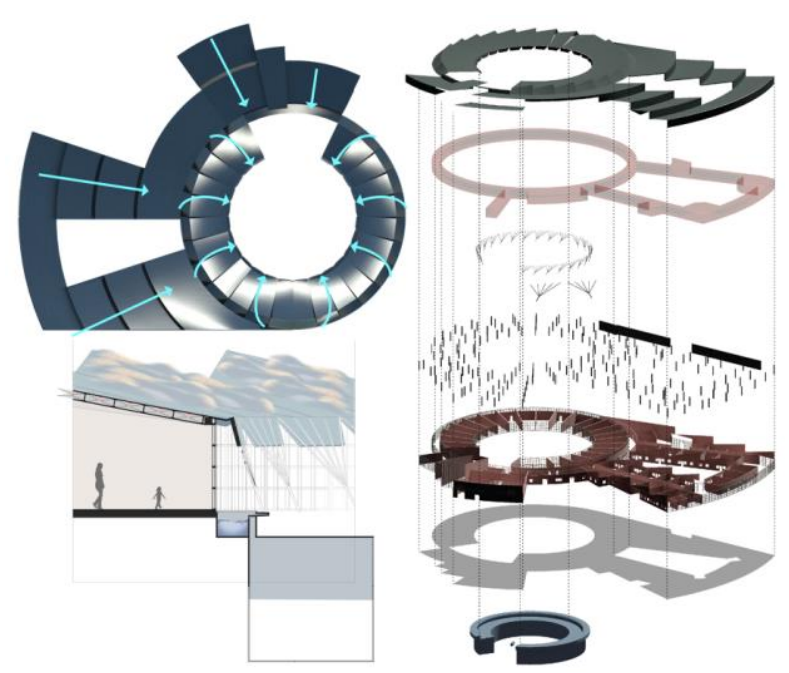

Figure 12: Top left: Direction of water collection from the roof; Bottom left: Wall section showing water collection toward the tank under the courtyard; Right: Exploded axonometric of the final building

\section{Project 4: Miami}

Site: The project's site as shown in Figure 13, is within a small commercial district of a mainly residential community. It is in a neighborhood known as Little Havana with a high crime rate.

Climate: Miami is in 1A ASHRAE climate zone and it is characterized by a very hot and humid climate. Miami's weather consists of consistent precipitation as well as heavy year-round humidity. There is also an abundance of sunlight in between the sporadic showers.
Climate-specific Resource Harvesting Method: Strong rains and high humidity are among the most critical environmental design considerations in this project. Thus, rainwater harvesting techniques were studied and the effect of roof geometry and slope on efficiency of precipitation collection was analyzed. The building structure as shown in Figure 15, collected and filtered the rainwater using a series of water tanks in between the classrooms visible in some parts for educational purposes and attached to indoor aquariums for classroom display. The filtration process of the water in the tanks prepare the water for consumption within the building and for plant irrigation. Table 6 shows the performance objective and performance indicators for the climate-specific harvesting system in this project.

\begin{tabular}{|c|c|c|}
\hline $\begin{array}{l}\text { Performance } \\
\text { Factor }\end{array}$ & Objective & Performance Indicator \\
\hline $\begin{array}{l}\text { Rainwater } \\
\text { harvesting }\end{array}$ & Maximize & $\begin{array}{l}\text { Collected Water (gallons) } \\
\text { Derived Parameters: } \\
\text { Roof area (sqft) } \\
\text { Tanks volume (cu ft.) }\end{array}$ \\
\hline
\end{tabular}

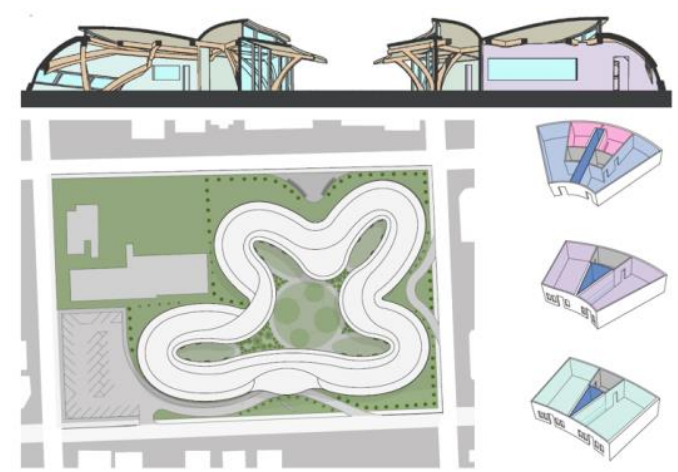

Figure 13: Top: Section through a courtyard showing the aquarium display; Bottom left: Miami project final site plan; Bottom left: Three modules of classrooms with the water tank in between in dark blue.

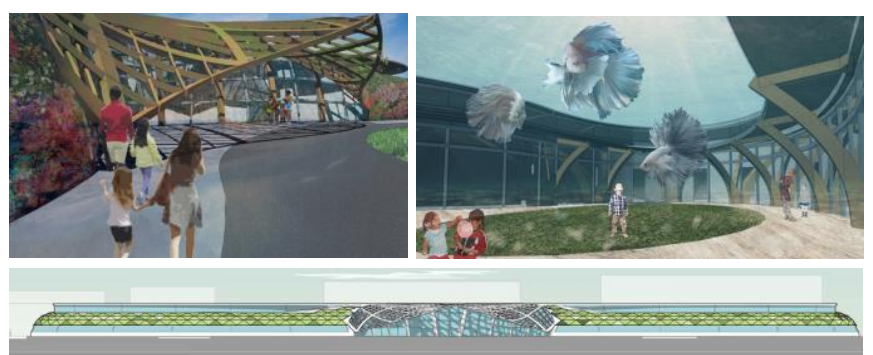

Figure 14: Top: Miami final building design; Bottom: South elevation

Design: During the second and third phase of the project, the team studied the effects of building form on rainwater collection as well as options for making water harvesting visible for kids. The initial concept of the building form was inspired by Cuban architecture to respond to the strong Cuban culture in Little Havana. Design alternatives were explored by performing a comparative analysis considering performance objectives and assessing tradeoffs. The team identified the strongest concepts as: the freeform shape that is indicative of the rich Cuban culture of the area, the communication between spaces across the courtyard, and rainwater harvesting with tanks within the building to inform their final design. The 
freeform organic shape as shown in Figure 13 and 14, mimics the fluidity of water as well. The project explored a curved roof shown in Figure 15, to enhance the daylighting in each space through the installation of high windows and facilitate rainwater harvesting. The concept's inward nature creates a protected safe building for the children. The indoor open play spaces are characterized by the triboelectric flooring system for interactive learning with an emphasis on the pathways.

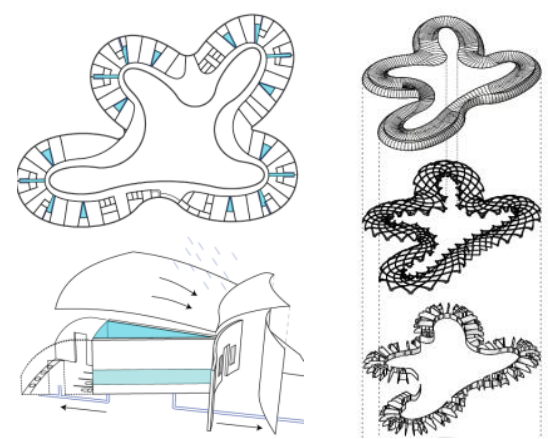

Figure 15: Top left: provision of water tanks and fish tank display in classrooms; Bottom left: Rainwater harvesting from the roof; Right: Exploded axonometric of the final building

\section{Discussion and Conclusion}

The performance-based design approach used in this study examined how multiple resource harvesting techniques can be integrated into the design process to enable the generation of design alternatives for further analysis and development. Figure 16 shows the data visualization for the Boston project based on the DSC methodology. In this diagram, the performance indicators are listed in columns and design alternatives including the final design are shown in rows. This Parallel Coordinate Plot (PCP) integrates design parameters i.e. performance indicators that have a relationship and provides an understanding to how these parameters affect the building design based on the performance objectives (Haymaker et al., 2017). The PCP maps variables for every design alternative and therefore, each contour line represents a design alternative with its corresponding values for the performance indicators.

This approach helps the decision-making process through the analysis and modifications of the design alternatives based on the performance objectives to achieve the optimal solution. The assessment of the tradeoffs is a fundamental step in this design approach. For instance, when considering daylighting for harvesting natural light, the performance objective is to maximize daylighting but there are two major aspects that should be considered:

a) An increase in daylighting requires more glazing surfaces which increases the energy consumption. Window-to-wall ratio (WWR) is one of the indicators that helps with the tradeoffs between maximizing the daylight factor and minimizing energy consumption. An increase in glazing surfaces can also minimize the provision of façade surfaces for the hydroponic wall installation which is supposed to be maximized. Therefore, "hydroponic wall area" indicator adds a new dimension in assessing the tradeoffs.

b) Daylighting can be increased by arranging building spaces along the outer edge of the building but this may cause an increase in the circulation spaces while the circulation distance needs to be minimized. Considering "maximum travel distance" indicator enables the evaluation of the tradeoffs.

In the Boston project shown in Figure 16, alternative 1, 2, and 3 (i.e. $A 1, A 2, A 3)$ was developed individually each as three design alternatives and $A 4$ is developed as the team combined design. When comparing these design alternatives, A3 has higher WWR (i.e. 0.5) than A4 (i.e. 0.4) and more overall daylight factor (i.e. 3.8) than A4 (i.e. 3.2) but A3 has higher energy consumption as its total thermal energy is about $307,000 \mathrm{kWh}$ and its heating load is $285,000 \mathrm{kWh}$. Also, A3 has less provision for hydroponic wall installation (i.e. 2500 sqft) which is the least among all four alternatives while in A4 more wall area is provided for hydroponic wall (i.e. $2900 \mathrm{sqft}$ ). In addition, since A3 distributes its spaces along the external wall to achieve a higher overall daylight factor, its maximum travel distance is $350 \mathrm{f}$ while the maximum travel distance in A4 is decreased to 280f. On the other hand, A1 has the highest daylight factor (i.e. 4.1) with the highest WWR (i.e. 0.6) and the highest total thermal energy (i.e. $375,000 \mathrm{kWh}$ ) and heating load (i.e. 342,000 kWh) but since in the design concept this alternative is arranging its spaces in two floors instead of one floor which is considered in A2 and A3, this alternative has the least maximum travel distance (i.e. 250f). As a result, A4 as the final design, took advantage of the concept of two-floor building to minimize its maximum travel distance. Among all four alternatives, A2 has the least glazing surfaces with the

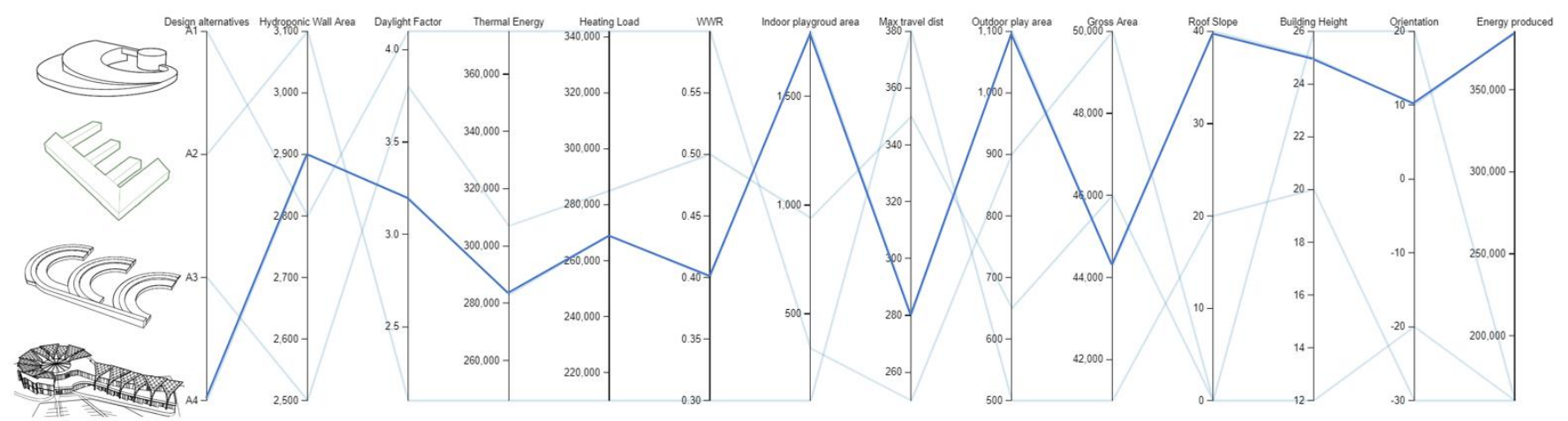

Figure 16: Parallel coordinate plot comparing Boston project's design alternatives based on performance indicators 
least WWR (i.e. 0.3) and therefore, its daylight factor is low (i.e. 2.1) and is the least among all alternatives.

Since some of the harvesting techniques are used as common solutions across the four projects, some indicators are the same in all projects such as, hydroponic wall area to maximize plant harvesting, daylight factor to maximize natural lighting, and indoor playground area to maximize energy harvesting from the triboelectric flooring system. Minimizing energy consumption is another factor that is included in all projects, because energy optimization focused on daylight and solar gains increase the energy efficiency of the buildings.

This study has explored a performance-based design methodology for integrating natural resource harvesting from the building envelope. The experiment and the study results indicate a design process that helps design thinking and decision-making through the identification of performance objectives and evaluation of the design alternatives based on the performance indicators. This integrates multi-objective resource harvesting technologies in the design of building. As the study shows, every climate will typically necessitate a different set of resource harvesting techniques to be integrated. Combining multiple harvesting techniques in buildings requires a complex decision making process because one harvesting technique might affect another as

\section{References}

ANSI/ASHRAE Standard 169-2013. "NORMATIVE APPENDIX BClimate Zones for U.S. States and Counties." Standard 169-2013: Climatic Data for Building Design Standards. Atlanta: ASHRAE, 2013. 71-85. Print.

American Society of Heating, Refrigerating and Air-Conditioning Engineers, Kuehn T. (2005) ASHRAE Handbook: Fundamentals, ASHRAE.

Chopra K., Das S.R. (1983) "Why Thin Film Solar Cells?" In Thin Film Solar Cells, pp 1-18, Springer.

Cho D., Hur J., Kilian T., Simon B., Strother J., Tait P., \& Vitiello N. (2017) Modular Green Wall. Atlanta, GA: Georgia Tech's School of Mechanical Engineering

Domenech L., Sauri D. (2011), A comparative appraisal of the use of rainwater harvesting, Journal of Cleaner Production, 19.

Evins R. (2013) A review of computational optimization methods applied to sustainable building design, Journal of Renewable and Sustainable Energy Reviews, 22.

Folke C., Carpenter S., Elmqvist T., Gunderson L., Holing C., Walker B. (2002), Resilience and Sustainable Development, Journal of the Human Environment, Royal Swedish Academy of Sciences.

Haymaker J., Bernal M., Bretchel J., Diaz S., Deckinga L., Hasan H., Marshall T., Okhoya V., Salveson A., Szilasi A., Kuehn P. (2017) explained in the example of daylighting and hydroponic wall. Also, the integration of natural resource harvesting with the building design can affect the design intend and the building geometry. To achieve an optimized solution, implementation of multiple resource harvesting techniques should follow a structured design process that allows the visibility of multiple, even conflicting performance objectives to facilitate the decision-making process. Future study will provide computational design methodologies that can automate the integration of multi-objective resource harvesting technologies with building design. Also, future study should consider additional performance objectives such as minimizing cost and the use of sustainable materials.

\section{Acknowledgments}

This research was jointly supported by the Digital Building Laboratory (DBL) and the School of Architecture at Georgia Tech. We thank the students in the course ARCH 3012/4012 during fall 2017 for their assistance: Katherine Martin, Aaron Weber, Gray Mitchell, Bangseh Akuchu, Liu Qiao, Takuto Osawa, Thomas Antonacci, Jessica Tolbert, Sherod Bryant, Samuel McGinnis, Candice Lee, and Daijah Suggs. We are also grateful to Dr. Shannon Yee, Dr. Amit Jariwala and the students in the School of Mechanical Engineering for their collaboration.

Design Space Construction (DSC) retrieved from http://designspaceconstruction.org/

Kilbert C., (2016) Sustainable Construction: Green Building Design and Delivery, Wiley.

McGee T., Pasvantis T., Goclon M., Hogenkamp J., \& Oke A. (2017) Sustainable Triboelectric Power System (STEPS). Atlanta, GA: Georgia Tech's School of Mechanical Engineering

NIBS (National Institute of Building Science) (2017) Whole Building Design Guide, Sustainable, retrieved from https://www.wbdg.org/design-objectives/sustainable.

Novak A., Van Giesen E., DeBusk K. (2014) Designing Rainwater Harvesting Systems: Integrating Rainwater into Building System

Shah A., Torres P., Tscharner R., Wyrsch N., Keppner H. (1999) "Photovoltaic Technology: The Case for Thin-Film Solar Cells", Science, pp 692-698.

United States Environmental Protection Agency. "Climate Change Indicators: U.S. and Global Temperature." EPA. Environmental Protection Agency, 17 Dec. 2016. Web. 21 July 2017.

Wang Z. (2014) Triboelectric nanogenerators as new energy technology and self-powered sensors - Principles, problems and perspectives, Journal of Faraday Discussions, 176, DOI: 10.1039/C4FD00159A. 